\title{
Multidisciplinary Constrained Optimization of Power Quality in Doubly Fed Wind Turbine Induction Generator
}

\author{
Seyed Javad Fattahi ${ }^{1}$, Abolghasem Zabihollah ${ }^{2}$ \\ ${ }^{1}$ Department of Mechanical Engineering, Ottawa University, Ottawa, Canada \\ ${ }^{2}$ School of Science and Engineering, Sharif University of Technology, Inter'l Campus, Kish Island, Iran \\ Email: sfattahi@uottawa.ca, zabihollah@kish.sharif.edu
}

Received October 16, 2012; revised March 21, 2013; accepted April 9, 2013

Copyright (C) 2013 Seyed Javad Fattahi, Abolghasem Zabihollah. This is an open access article distributed under the Creative Commons Attribution License, which permits unrestricted use, distribution, and reproduction in any medium, provided the original work is properly cited.

\begin{abstract}
Shape optimization of turbine blade to maximize the output power usually changes the power factor due to compensate Repower in a wind turbine. This article presents a multidisciplinary optimization technique to maximize the output power in Doubly Fed Induction Generator (DFIG) wind turbine. The most common parameters when operating the turbine, namely, active power, reactive power and power factor, are considered as the problem constraints and the pitch angle grid side variable frequency converter of the turbine blades are optimized to maximize the output power. Numerical simulation has been illustrated to present the performance of the proposed design approach.
\end{abstract}

Keywords: Optimization; DFIG; WTG; Pitch Angle; RSC; GSC

\section{Introduction}

Wind Turbine machines are rapidly becoming an economically viable source of renewable energy. Two key elements of wind turbine, performance and availability, serve optimization based on machine design and performance. Wind turbine performance could be characterized by three basis parameters for power, torque and the load of the tower of a wind turbine. The torque size is important to design the mechanical elements like the rotor, gear box and brake. The tower of the wind turbine and foundation are designed to resist against the compression, buckling and the axial loading. The power size is important because it affects the transformed energy by the rotor of wind turbine. Therefore, power quality is a new challenge in wind turbine design [1-3]. Harmonics generated by the interactive wind system were investigated by Giraud and Salameh [4]. Boukhezzar et al. [5] proposed a non-linear approach to control a variablespeed turbine to maximize the power of turbine considering the generator torque. Muljadi and Butterfield [6] developed a pitch control strategy to maximize the power and minimize turbine loads for different wind speed scenarios. Chen et al. in [7] proposed the reactive power optimization of the distribution network which contains several wind farms by introducing the static VAR compensators, and Bie et al. in [8] present a transition-opti- mized approach based on adaptive load pattern classification for DFIG based on the fluctuation of the output active power and the reactive power capability and this procedure was completed in [9]. Also in [10-12], different multi-objective particle swarm optimization (MOPSO) is proposed where MOPSO considers multi-objective simultaneously rather than a PSO but the output of MOPSO consists of a group of non-dominated instead of PSO that it has only one optimization solution, but these papers focus on active and reactive power of DFIG and grid, on the other hand, Kusiak and Zheng [13] introduced an evolutionary computation approach for optimization of power factor and power output of wind turbines. This article contributes a multidisciplinary optimization for doubly Fed Induction Generator (DFIG) wind turbine subjected to active power, reactive power and power factor mutually, through pitch angle and grid side variable frequency converter. Numerical simulation has been illustrated to present the performance of the proposed design approach.

\section{Wind Active Power}

Theoretically, using Betz's model, wind energy captured by the rotor of a wind turbine can be expressed by:

$$
P_{r}=0.5 \rho \pi R^{2} C_{p}(\lambda, \beta) v_{1}^{3}
$$


where $P_{r}, \rho, \mathrm{R}$ and $v_{1}$ represent, respectively, the wind energy captured by the rotor, the air density, the rotor radius, and wind speed before passing the rotor. The parameter $C_{p}$ is the power coefficient that depends on the blade pitch angle, $\beta$, and the tip-speed ratio, $\lambda$, and can be determined from the following relation as:

$$
\begin{gathered}
C_{p}=4\left(\frac{v_{2}}{v_{1}}\right)^{3}\left(1-\frac{v_{2}}{v_{1}}\right) \\
v_{2}=\frac{v_{3}+v_{1}}{2} \\
\lambda=\frac{\omega_{r} R}{v_{2}}
\end{gathered}
$$

where $\omega_{r}$ is the rotational speed of the rotor and $v_{1}$ and $v_{3}$ are wind speed in front and behind of turbine blade respectively. The literature on optimization of the power coefficient $C_{p}$ is quite extensive. The maximum value of the power coefficient $C_{p}$ is obtained by the derivation of (2) and optimal value of $v_{2} / v_{1}$ is equal to 0.593 .

A wind turbine may operate when the tip speed ratio is changing in large limits but a maximum power coefficient, $C_{p}$, could be obtained only for an optimal value of $\lambda$ (tip speed ratio). It results that the maximum efficiency in the wind energy conversion and the rotational speed of the rotor wind turbine must be correlated with the wind speed.

Wind turbines with capability to control the pitch angle may have the power coefficient described by a function that depends on pitch angle and tip speed ratio:

$$
C_{p}(\lambda, \beta)=C_{1}\left(C_{2} \lambda_{i}-C_{3} \beta-C_{4}\right) \mathrm{e}^{-c_{5} \lambda_{i}}+C_{6} \lambda
$$

where:

$$
\lambda_{i}=\frac{1}{\lambda+0.08 \beta}-\frac{0.035}{\beta^{3}+1}
$$

The variables $C_{i}$ are given as: $C_{1}=0.5175, C_{2}=116$, $C_{3}=0.4, C_{5}=5, C_{6}=21$ [14]. Figure 1 shows the generated power with respect to different wind speed when pitch angle equal to zero in which one may conclude that the generated power has a large sensitivity to pitch angle. The power coefficient $C_{p}$ for the pitch angle $\beta$ variation from $0^{\circ}$ to $20^{\circ}$ is shown in Figure 2.

\section{Sensitivity Analysis}

Design optimization of wind turbine generators using pitch angle does not guarantee that the power quality of the output power to be desirable. Numerically, for rotor speed of $54 \mathrm{rpm}$, zero pitch angle and the maximum $C_{p}$ of 0.4296 , the tip speed ratio is obtained as 7.9952 .

It is worth noting that the variation of the rotor speed is limited by the gear constraint and it is allowed to tolerate $\pm 5 \%$. As it is shown in Figure 3, the maximum output power has a large sensitivity to set point of the working rotor speed. Figure 4 shows the graph of the working plane of a WTG for different rotor speed and wind speed. It is shown that in desired wind speed (around $13.5-14.5 \mathrm{~m} / \mathrm{s}$ ) the output power is changed from $82 \%-107.5 \%$ of nominal ( $0.95 \mathrm{MW}$ ) output power, hence, for delivering a good power quality, multiple variables, including pitch angle, rotor speed limitation or generated reactive power need to be controlled simultaneously.

The power is given as:

$$
S^{2}=P^{2}+Q^{2}
$$

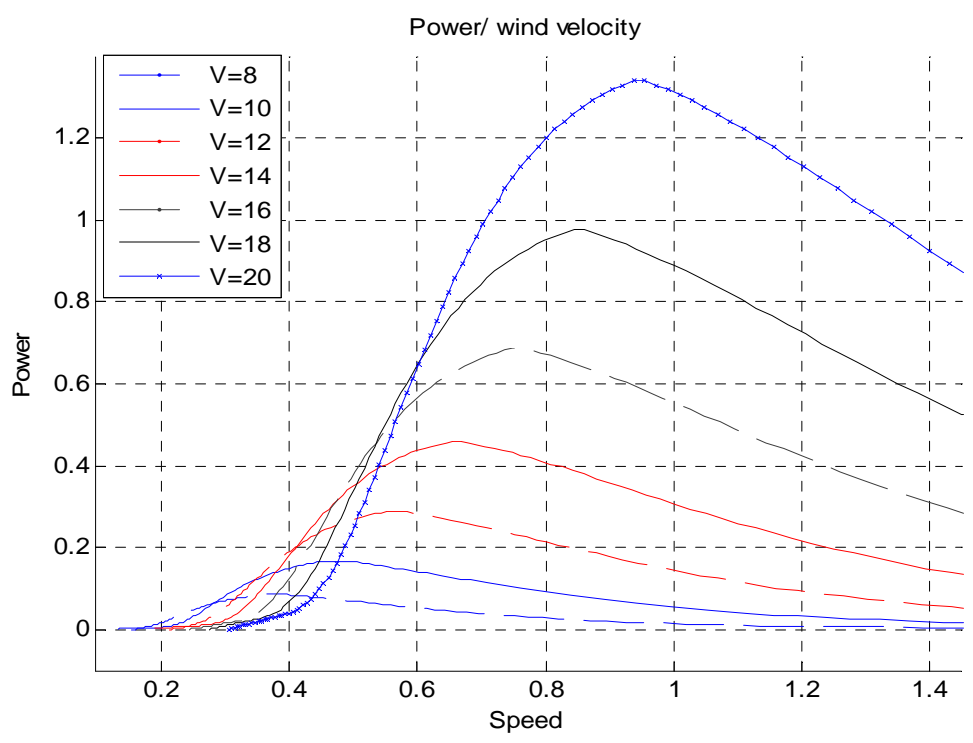

Figure 1. Output power in different wind speed with respect to $\beta=0^{\circ}$. 


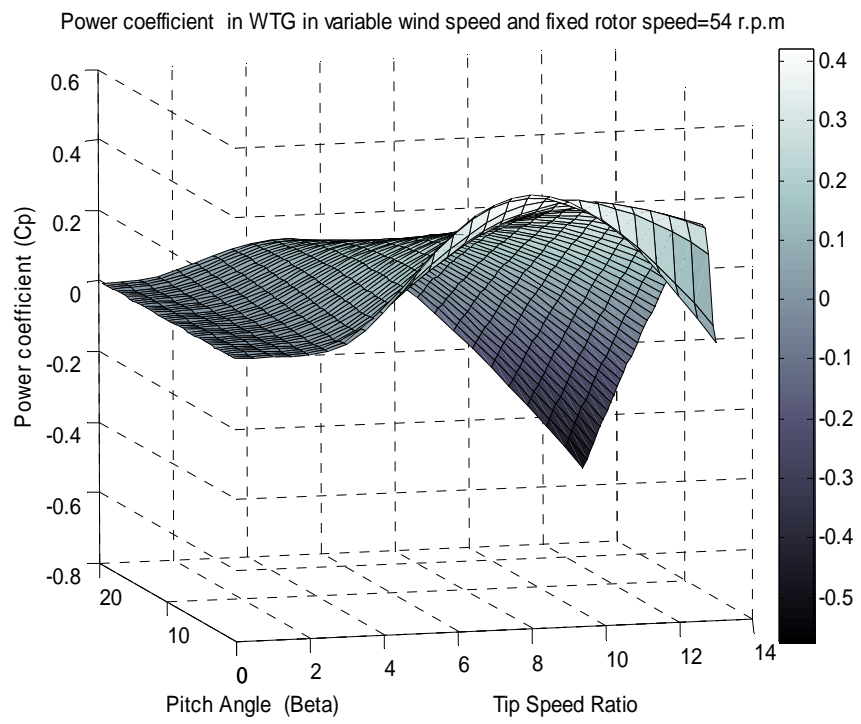

Figure 2. Power coefficient in WTG in variable wind speed and fixed rotor speed 54 r.p.m.

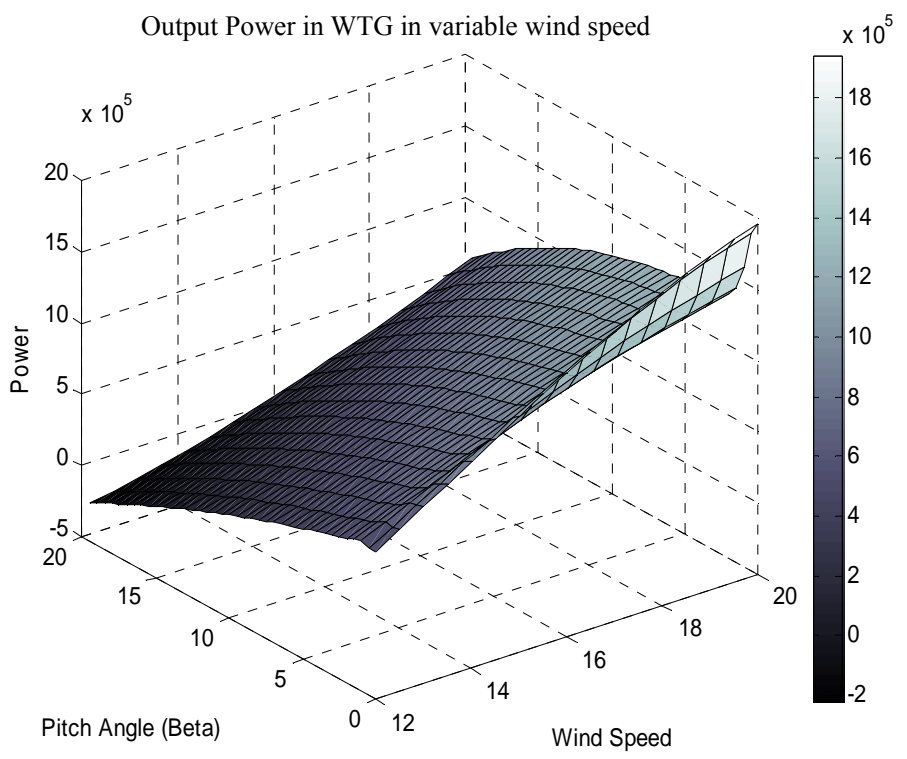

Figure 3. Output power of WTG in when speed of wind and pitch angle varies.

where $P$ is the stator active power measured in Watts (W), $S$ is the apparent power measured in volt-amperes (VA), $Q$ is the reactive power measured in reactive voltamperes. The Power factor is given by $\cos (\Phi)=P / S$, where $\Phi$ is the phase angle between the current and the voltage, measured in degrees.

\subsection{Reactive Power Sensitivity}

The reactive power flow from the grid to the wind plant at the interconnecting point is simplified and given by [15]:

$$
Q_{t}=Q_{g}+3 I^{2} X-V^{2}(2 \pi f) C-Q_{c}
$$

where $Q_{g}$ is the positive reactive power, consumption, of the turbine which is also negative when WTG is operating at a lagging power factor, $X$, denotes the equivalent series reactance of cables, lines and transformers, $C$ is the equivalent shunt reactance of cables, and $Q_{c}$ is the reactive-power injected by any reactive power compensation system at the point of interaction. The second and third terms of Equation (8) are not controllable and approximately, fixed in steady state, thus, control of $Q_{t}$ has to be done with $Q_{g}$ and $Q_{c}$ only. The wind turbine is connected to the Doubly Fed Induction Generators (DFIG) through a mechanical shaft system, which consists of a low-speed and a high-speed shaft which are connected with a gearbox. The wound-rotor induction 


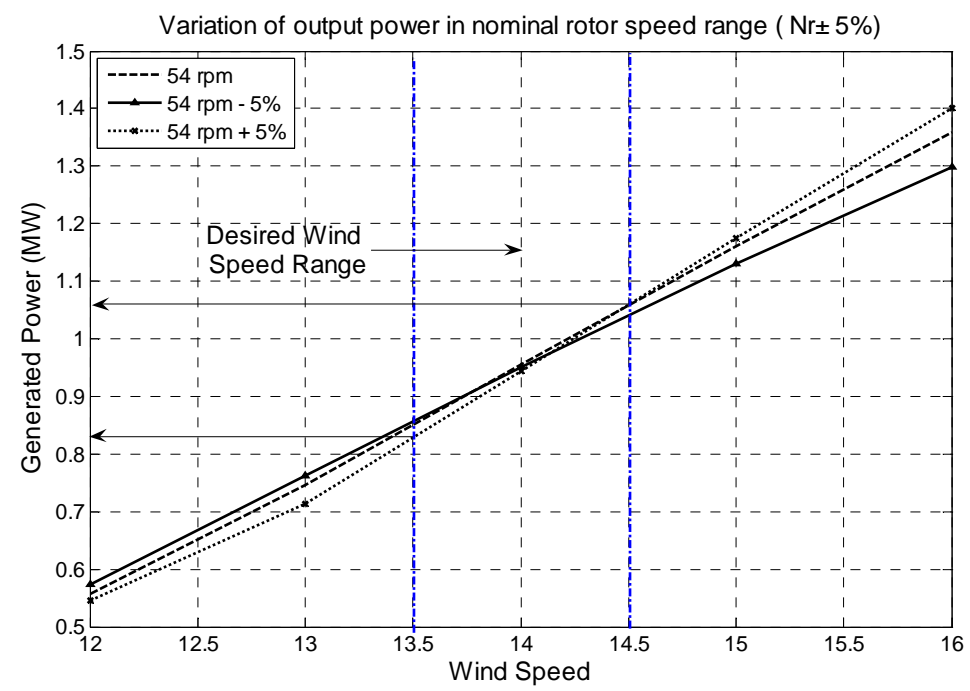

Figure 4. Generated power of WTG with constraint to rotor speed and wind speed.

machine in this configuration is fed from both stator and rotor sides. The stator is directly connected to the grid while the rotor is fed through a variable frequency converter (VFC). In order to produce electrical active power at constant voltage and frequency to the utility grid over a wide operation range from sub-synchronous to supersynchronous speed, the active power flow between the rotor circuit and the grid must be controlled both in magnitude and in direction. In DFIG the variable frequency converter consists of two four-quadrant IGBT PWM converters, rotor-side converter (RSC) and gridside converter (GSC), connected back-to-back by a de link capacitor. The crow-bar is used to short-circuit the RSC in order to protect the RSC from over-current in the rotor circuit during transient disturbances. The RSC control scheme is expected to achieve the following objectives [16].

1) Regulating the DFIG rotor speed for maximum wind power capture

2) Maintaining the DFIG stator output voltage frequency constant

3) Controlling the DFIG reactive power

Normally, for Doubly Fed Induction Generators (DFIG), the reactive power consumption depends on the terminal voltage and loading according to the following expressions $[16,17]$ :

$$
\begin{gathered}
P=-V_{s} \frac{L_{m}}{L_{s}} I_{q r} \\
Q_{g}=\frac{3}{2} \frac{\omega_{s} L_{m}^{2} I_{m s}\left(I_{m s}-I_{d r}\right)}{L_{s}} \\
I_{m s}=\frac{V_{q s}-R_{s} I_{q s}}{\omega_{s} L_{m}}
\end{gathered}
$$

where, $I_{d r}$ is rotor current in $d$-axis, $L_{s}$ and $L_{m}$ are stator leakage and velocity ( $\mathrm{rad} / \mathrm{s})$ and $V_{q s}$ is the magnitude of the stator phase voltage in $q$-axis. The reactive power can be controlled on the terminals of the machine or at the grid side of the turbine transformer within the WTG capability. The voltage variations are much less than the current variation, therefore, the current is the main term that is required for compensation. Thus, by using vector control with d-axis oriented stator flux vector in rotor side converter (Equations (10) and (11)), the stator reactive power $Q_{g}$ can be controlled by regulating $I_{d r}$.

On the other hand, grid side converter is presented for keeping DC-link voltage of capacitor constant, regardless of the magnitude and direction of rotor power. Neglecting the power losses in the converter, capacitor current can be described as follow [12]:

$$
I_{D C}=\frac{3}{4} k I_{d g c}-I_{r D C}
$$

where $I_{d g c}$ stands for the $d$-axis current flowing between grid and grid side converter, $I_{r D C}$ is the rotor side $D C$ current, $C$ is the $D C$-link capacitance, and $k$ is the PWM modulation index of the grid side converter. The reactive power flow into the grid from GSC can be expressed as:

$$
Q_{c}=\frac{3}{2} V I_{q g c}
$$

where $V$ is the magnitude of grid phase voltage $(V)$ and $I_{q g c}$ is q-axis current of grid side converter $(A)$. Therefore, it is seen from Equations (11) and (12), by adjusting $I_{d g c}$ and $I_{q g c}, D C$-link voltage and $Q_{c}$ can be controlled respectively.

Using Equations (10) and (13), the DFIG reactive power can be written as: (See Equation (14)). 
The power factor measures the efficiency of electric power utilization. The wind turbines are controlled to maintain a power factor of 1 . Substituting Equations (9) and (14) in Equation (8), leads to:

$$
\begin{aligned}
& S^{2}=K\left[\left(I_{q r}\right)^{2}+\left(I_{d r}-\frac{\varphi_{s}}{L_{m}}\right)^{2}\right] \\
& K=\left(-V_{s} \frac{L_{m}}{L_{s}}\right)^{2}
\end{aligned}
$$

However, the power factor of wind turbines is difficult to control, thus, its value is lower than 1 for individual wind turbines and wind farms. Figure 5 shows the active vs reactive power generation curve, in which one can observe that ideal point $(S=P)$ occurs at "0.99 Pmax". On the other hand, it is known that the generated power is highly sensitive to power coefficient and pitch angle ratio. Therefore, to reach to a desired power factor in grid several variables should be taken into consideration simultaneously, requiring a multidisciplinary optimization technique.

\section{The Optimization Problem}

The limitations imposed by ambient temperature on the power electronic device, is less restrictive than those fixed by the generator itself. Consequently, the generator must be kept in a safe operation zone. Safe operation zone depends on the type of inverter and generator which is considered as $95 \%$ of full power capacity. Optimization of power quality needs solving two optimization problems: 1) maximization of active power and 2) minimization of reactive power, therefore, requiring a multidisciplinary optimization problem to be solved.

\subsection{Statement of Optimization Problem}

The optimization problems have been cast into a standard format as: (See Equation (19)).

subject to:

$$
\begin{gathered}
0<\beta<5 \\
0<\omega_{r} R / v_{2}<14 \\
12<v_{1}<16 \mathrm{~m} / \mathrm{s}
\end{gathered}
$$

Minimizing

$$
\begin{aligned}
& Q\left(I_{d r}, I_{m s}, V, f\right) \\
& =\frac{3}{2} \frac{\omega_{s}\left(2 \pi f x_{m}\right)^{2} I_{m s}\left(I_{m s}-I_{d r}\right)}{L_{s}}+\frac{3}{2} V I_{q g c} a
\end{aligned}
$$

subject to:

$$
\begin{aligned}
& 0.95<s_{r}<1.05 \mathrm{Pu} \\
& \frac{V_{q s}-R_{s} I_{q s}}{\omega_{s} L_{m}}=I_{d r} \\
& 180<V_{q s}<240 \text { Volt }
\end{aligned}
$$

In general, the pitch angle $(\lambda)$, tip speed ratio $(\beta)$, wind speed $(v)$ and rotor speed $\left(S_{r}\right)$ are related constraints of generated active power and $I_{d r}, I_{m s}, V$ and $f$ are related constraints of reactive power.

\subsection{Statement of Multidisciplinary Optimization Problem}

The objective of Multidisciplinary optimization problem is defined as:

Maximize $S$ through ;

$$
S=\sqrt{P^{2}+Q^{2}}
$$

The solution of this problem has been performed as the following:

Solving the maximization problem described at $\mathrm{i}$ without any optimizing procedure on reactive power " $Q$ ", or vice versa, means solving minimization problem described at ii without any optimizing procedure on active power " $P$ "; both procedures lead to bad power quality output from DFIG. Therefore, it needs to define a Multidisciplinary Optimization (MDO) control in two different domains: 1) MDO is based on active power optimization by using the pitch angle, tip speed ratio, and wind velocity and 2) reactive power optimization by using rotor speed, $d$-axis of rotor current, $q$-axis of stator current and voltage simultaneously and priority concern. The priority of solving optimization Problem (1) and Problem (2) depends on the results obtained from each section. This fact has been clearly presented in results provided in Tables 1-3. These two problems have been solved using Sequential Quadratic Programming (SQP)

$$
\begin{gathered}
Q=\frac{V_{s} \varphi_{s}}{L_{s}}-V_{s} \frac{L_{m}}{L_{s}} I_{d r}=Q_{g}+Q_{c}=\frac{3}{2} \frac{\omega_{s} L_{m}^{2} I_{m s}\left(I_{m s}-I_{d r}\right)}{L_{s}}+\frac{3}{2} V I_{q g c} \\
P\left(\lambda, \beta, v, S_{r}\right) \\
=0.5 \rho \pi R^{2} \cdots\left\{C_{1}\left(C_{2}\left(\frac{1}{\lambda+0.08 \beta}-\frac{0.035}{\beta^{3}+1}\right)-C_{3} \beta-C_{4}\right) * \mathrm{e}^{\left.-c_{5}\left(\frac{1}{\lambda+0.08 \beta}-\frac{0.035}{\beta^{3}+1}\right) \cdots+C_{6} \lambda\right\} v_{1}^{3}}\right.
\end{gathered}
$$




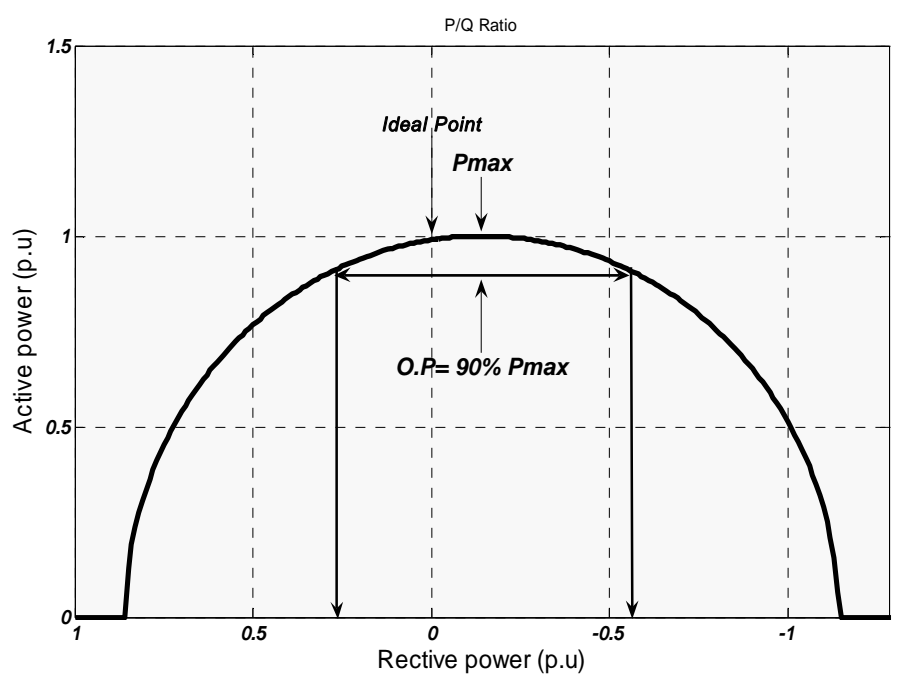

Figure 5. Active vs. reactive power generation curve in DFIGWTG.

approach described in the following section. One may note that due to complexity of the solution procedure and as the (SQP) is a well-defined optimization technique in many commercial packages, including MATLAB ${ }^{\circledR}$, here, only the basis of the (SQP) is provided. However, to enhance the accuracy and for faster convergence to optimal results, the gradients of the objective and constraints functions have been computed analytically and fed to the optimization toolbox of MATLAB ${ }^{\circledR}$.

\subsection{Sequential Quadratic Programming (SQP)}

The optimization problem is formulated as Sequential Quadratic Programming (SQP) which is a widely used method for most complex nonlinear optimization problems owing to its robustness and high efficiency in searching for the optimum point. Considering a general problem of minimizing the objective function $f(x)$, subject to constraint $(x)$, we can write the Lagrangian function as

$$
L\left(\left\{x_{k}\right\}, \lambda\right)=f(\{x\})+\sum_{i=1}^{m} \lambda_{i} g_{i}\left(\left\{x_{k}\right\}\right)
$$

Then the quadratic programming (QP) sub-problem can be formulated based on a quadratic approximation of the Lagrangian function as:

$$
\min _{d \in R^{n}} \frac{1}{2} d^{\mathrm{T}} H_{k} d+\delta f\left(q_{k}\right)^{\mathrm{T}} d
$$

Subject to

$$
\begin{aligned}
& \nabla g_{i}\left(x_{k}\right)^{\mathrm{T}} d+g_{i}\left(x_{k}\right)=0 \\
& \nabla \lambda_{i}\left(x_{k}\right)^{\mathrm{T}} d+\lambda_{i}\left(x_{k}\right) \leq 0
\end{aligned}
$$

Here $x_{k}, g_{i}$ and $\lambda_{i}$ are design variable vector, constraint functions and Lagrange multipliers, respectively.
Table 1. Maximum output power and recommended priority of control in normal rotor speed (54 r.p.m).

\begin{tabular}{cccc}
\hline$\beta$ & $\begin{array}{c}\text { Wind Speed } \\
(\mathrm{m} / \mathrm{s})\end{array}$ & $\begin{array}{c}\text { Max Power } \\
\text { MW }\end{array}$ & $\begin{array}{c}\text { Reactive Power Control } \\
\text { Priority }\end{array}$ \\
\hline 0 & 12 & 0.53943 & RSC, GSC, Pitch \\
0 & 13 & 0.74516 & RSC, GSC, Pitch \\
0.07196309 & 14 & 0.95 & RSC, Pitch, GSC \\
1.39194002 & 15 & 0.95 & Pitch, RSC, GSC \\
3.12291662 & 16 & 0.95 & Pitch, RSC, GSC \\
\hline
\end{tabular}

Table 2. Maximum output power and recommended priority of control in rotor sub-speed (54 × 0.95 r.p.m).

\begin{tabular}{cccc}
\hline$\beta$ & $\begin{array}{c}\text { Wind Speed } \\
(\mathrm{m} / \mathrm{s})\end{array}$ & $\begin{array}{c}\text { Max Power } \\
\text { MW }\end{array}$ & $\begin{array}{c}\text { Reactive Power Control } \\
\text { Priority }\end{array}$ \\
\hline 0 & 12 & 0.57310 & RSC, GSC, Pitch \\
0 & 13 & 0.76210 & RSC, GSC, Pitch \\
0.00351158 & 14 & 0.95 & RSC, Pitch, GSC \\
1.10133779 & 15 & 0.95 & Pitch, RSC, GSC \\
1.83905968 & 16 & 0.95 & Pitch, RSC, GSC \\
\hline
\end{tabular}

Table 3. Maximum output power and recommended priority of control in rotor super-speed (54 × 1.05 r.p.m).

\begin{tabular}{cccc}
\hline$\beta$ & $\begin{array}{c}\text { Wind Speed } \\
(\mathrm{m} / \mathrm{s})\end{array}$ & $\begin{array}{c}\text { Max Power } \\
\text { MW }\end{array}$ & $\begin{array}{c}\text { Reactive Power Control } \\
\text { Priority }\end{array}$ \\
\hline 1.1525 & 12 & 0.54649 & Pitch, RSC, GSC \\
0.8616 & 13 & 0.71390 & Pitch, RSC, GSC \\
0 & 14 & 0.94356 & RSC, Pitch, GSC \\
1.76758958 & 15 & 0.95 & Pitch, RSC, GSC \\
4.39396085 & 16 & 0.95 & Pitch, RSC, GSC \\
\hline
\end{tabular}


The matrix $H_{i}$ is a positive definite approximation of the Hessian matrix of the Lagrangian function and can be updated by using quasi-Newton methods. The solution to the sub-problem is then used to form a new iteration until convergence occurs.

To improve the chances of obtaining a minimum closer to global minimum, a trial-and-error or heuristic approach is used together with the SQP method. A simple heuristic method involves randomly selecting a set of starting points in the hope that one of these starting points is close to the global minimum. While global minimum is not assured, the probability of obtaining better minimum increases with the number of starting points. Examining Equations (23) and (24), one can easily realize that the gradients of objective and constraint functions, $f(\{x\})$ and $g_{i}\left(\left\{x_{k}\right\}\right)$ are the most dominant factor in convergence of the optimization procedure. As it mentioned above, in order to reach the global optimum the procedure should be repeated for different starting points, requiring an efficient computations of the function gradients. In the present work, the analytical gradients of objective and constraint functions have been derived and implemented in SQP method for all the optimization problems unless otherwise specified.

Solving the optimization problem described above, leads to the maximum power output for normal, subspeed and super-speed rotor values. Table 1 provides the maximum power output for normal speed (54 r.p.m), in which one can conclude that the maximum power obtains at wind speed of $16 \mathrm{~m} / \mathrm{s}$ and $\beta=3.12^{\circ}$ Table 2 provides the maximum power output for rotor sub-speed (54 $\times 0.95$ r.p.m), in which, once again, the maximum power obtains at wind speed of $16 \mathrm{~m} / \mathrm{s}$ and $\beta=1.84^{\circ}$ and the priority in control is similar that of normal rotor speed. For super-speed of rotor $(54 \times 1.05$ r.p.m), the maximum power achieves at $\beta=4.39^{\circ}$ as given in Table 3 . It is worth noting that to obtain the maximum power; the priority in control for normal, sub-speed and super-speed is always recommended as: Pitch, RSC, GSC.

\section{Modeling and Simulation}

By simulating the DFIG that it's connected directly to the network through the stator, and controlled by its rotor through a PWM direct torque control converter, based on a vector control approach via stator flux. The simultaneous control methodology is implemented and simulated on DFIG based on pitch angle control, rotor-side converter (RSC) control and grid-side converter (GSC) control. Figure 6 shows the regulated speed of GFIG rotor,and it is shown that the rotor speed remained fixed to nominal speed (54 r.p.m)when the wind speed is varied in step down and up to $13 \mathrm{~m} / \mathrm{sand} 15 \mathrm{~m} /$ srespectively. Figure 7 shows the rotor current regulated in DFIG by using PWM converter on rotor side. Finally, the delivered cur- rent (stator current) to grid side is presented in Figure 8, in which one can see that after 0.2 second the delivered power (current) to the grid is remained constant, and it's calculated RMSE value is $0.43 \%$ after steady state time (after $500 \mathrm{~ms}$ ) by concurrent using of RSC, GSC, Pitch and PWM control together.

\section{Conclusion}

A multidisciplinary optimization technique has been

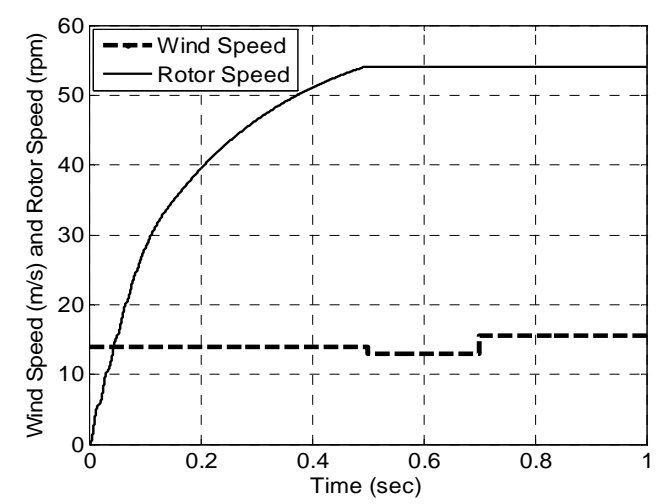

Figure 6. Rotor speed of DFIG in variable wind speed.

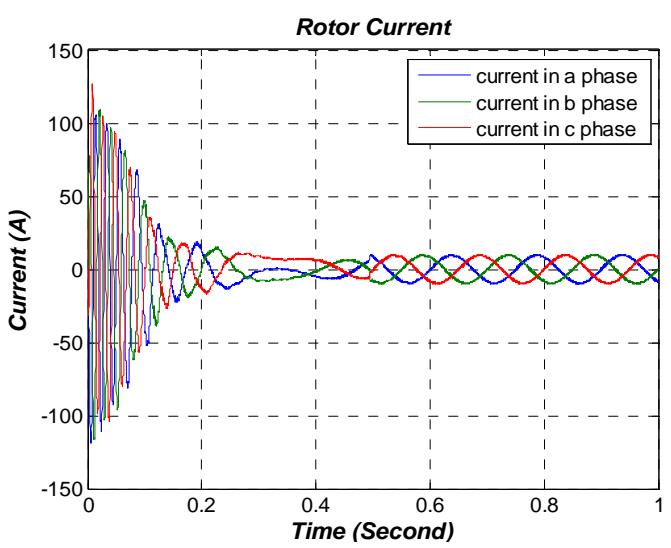

Figure 7. Regulated rotor current in DFIG in variable wind speed.

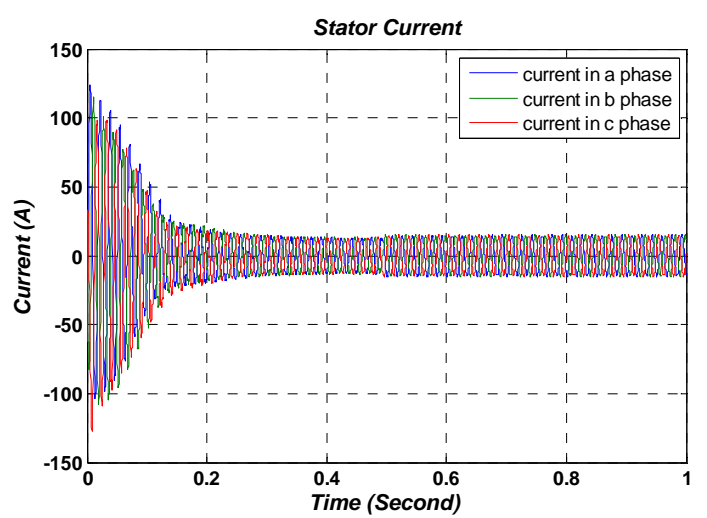

Figure 8. Stator current in DFIG in variable wind speed. 
presented to maximize the power generated of Doubly Fed Induction Generator (DFIG) wind turbine. The most common constraints, namely, active power, reactive power, power factor, pitch angle and grid side variable frequency converter has been taken into consideration. The design and operation optimization problems have been considered and solved simultaneously to determine the optimal pitch angle and power control. It is observed that optimizing the pitch angle is not sufficient to maximize the generated power. It may cause an undesired power quality in grid, requiring a multi-disciplinary optimization approach to obtain the optimum power quality.

\section{REFERENCES}

[1] A. Tapia, G. Tapia and J. X. Ostolaza, "Reactive Power Control of Wind Farms for Voltage Control Applications," Renewable Energy, Vol. 29, No. 3, 2004, pp. 377392.bdoi:10.1016/S0960-1481(03)00224-6

[2] A. Dittrich, W. Hofmann, A. Stoev and A. Thieme, "Design and Control of a Wind Power Station with Double Fed Generator," 7th European Conference on Power Electronics and Application, Trondheim, 8-10 September 1997, pp. 723-728.

[3] S. H. Jangamshetti and V. Guruprasada Rau, "Normalized Power Curves as a Tool for Identification of Optimum Wind Turbine Generator Parameters," IEEE Transactions on Energy Conversion, Vol. 16, No. 3, 2001, pp. 283-288. doi:10.1109/60.937209

[4] F. Giraud and Z. M. Salameh, "Measurement of Harmonics Generated by an Interactive Wind/Photovoltaic Hybrid Power System," Electric Power Components and Systems, Vol. 35, No. 7, 2007, pp. 757-768. doi: $10.1080 / 15325000601175132$

[5] B. Boukhezzar, H. Siguerdidjane and M. Maureen Hand, "Nonlinear Control of Variable-Speed Wind Turbines for Generator Torque Limiting and Power Optimization," ASME Transactions: Journal of Solar Energy Engineering, Vol. 128, No. 4, 2006, pp. 516-530. 2006doi:10.1115/1.2356496

[6] E. Muljadi and C. P. Butterfield, "Pitch-Controlled Variable-Speed Wind Turbine Generation," IEEE Transactions on Industry Applications, Vol. 37, No. 1, 2003, pp. 240-246. doi:10.1109/28.903156

[7] L. Chen, J. Zhong, Y. X. Ni, D. Q. Gan, et al., "Reactive Power Optimization in Distribution Network Including
Distributed Generators," Automation of Electric Power Systems, Vol. 30, No. 14, 2006, pp. 20-24.

[8] Z. H. Bie, Y. H. Song, X. F. Wang, G. A. Taylor and M. R. Irving, "A Transition-Optimized Approach to Reactive Power and Voltage Control," IEEE Power Engineering Society General Meeting, Denver, 6-10 June 2004, pp. 226232.

[9] Z. Jiang, J. Chen, N. Li, M. Yao and H. Li, "Dynamic Optimization of Reactive Power and Voltage Control in Distribution Network Considering the Connection of DFIG,' Power Engineering and Automation Conference (PEAM), Wuhan, 8-9 September 2011, pp. 30-34.

[10] C. A. C. Coello and M. S. Lechuga, "MOPSO: A Proposal for Multiple Objective Particle Swarm Optimization," Proceedings of the 2002 Congress on Evolutionary Computation, Honolulu, 12-17 May 2002, pp. 1051-1056.

[11] H. Radwan, A. Hamid Amr, M. A. Amin Refaat, S. Ahmed Adel and A. A. El-Gammal, "Optimal Operation of Induction Motors Based on Multi-Objective Particle Swarm Optimization (MOPSO)," The 33rd Annual Conference of the IEEE Industrial Electronics Society (IECON), Taipei 5-8 November 2007, pp. 1079-1084.

[12] A. Laifa and B. Mohamed, "FACTS Allocation for Power Systems Voltage Stability Enhancement Using MOPSO," 5th International Multi-Conference on Systems, Signals and Devices, Amman, 20-22 July 2008, pp. 1-6.

[13] A. Kusiak and H. Y. Zheng, "Optimization of Wind Turbine Energy and Power Factor with an volutionary Computation Algorithm," Energy, Vol. 35, No. 3, 2010, pp. 1324-1332. doi:10.1016/j.energy.2009.11.015

[14] S. Heier, "Grid Integration of Wind Energy Conversion Systems," John Wiley \& Sons Ltd., Hoboken, 1998.

[15] R. Pena, J. C. Clare and G. M. Asher, "Doubly Fed Induction Generator Using Back-to-Back PWM Converters and Its Application to Variable Speed Wind-Energy Generation," Proceedings of the Institute of Electrical and Electronics Engineers (IEEE), Vol. 143, No. 3, 1996, pp. 231-241.

[16] A. Petersson, L. Harnefors and T. Thiringer, "Evaluation of Current Control Methods for Wind Turbines Using Doubly-Fed Induction Machines," IEEE Transactions on Power Electronics, Vol. 20, No. 1, 2005, pp. 227-235. doi:10.1109/TPEL.2004.839785

[17] Q. Wei, "Wind Speed Estimation Based Sensor Less Output Maximization Control for a Wind Turbine Driving a DFIG," IEEE Transactions on Power Electronics, Vol. 23, No. 3, 2008. 